\title{
A knowledge-based perspective on system weaknesses in technological innovation systems
}

\author{
Johan Frishammar ${ }^{1, *}$, Patrik Söderholm², Hans Hellsmark ${ }^{3,4}$ and \\ Johanna Mossberg ${ }^{5}$
}

${ }^{1}$ Luleå University of Technology, Entrepreneurship \& Innovation, Sweden, ${ }^{2}$ Luleå University of Technology, Economics Unit, Sweden, ${ }^{3}$ Chalmers University of Technology, Sweden, ${ }^{4}$ Zhejiang University, China and ${ }^{5}$ Research Institutes of Sweden (RISE), Division of Bioeconomy, Sweden

*Corresponding author. Email: johan.frishammar@|tu.se

\begin{abstract}
The literature on technological innovation systems (TIS) provides policymakers and other actors with a scheme of analysis to identify system weaknesses. In doing so, TIS analysis centres on which system weaknesses policy interventions should target to promote further development of a particular system. However, prior TIS literature has not sufficiently elaborated on what may constitute the conceptual roots of a 'weakness'. We apply a knowledge-based perspective and propose that many-albeit not all-system weaknesses may root in four types of knowledge problems: uncertainty, complexity, equivocality, and ambiguity. Employing these as sensitizing concepts, we study system weaknesses by analysing data from a biorefinery TIS in Sweden. This analysis results in novel implications for the TIS literature and for achieving a better match between system weaknesses and the design of innovation policies.
\end{abstract}

Key words: technological innovation system; system weakness; uncertainty; complexity; equivocality; ambiguity

\section{Introduction}

A technological innovation system (TIS) comprises actors, networks, institutions, and technology. It is a dynamic socio-technical system in which actors collaborate within a particular institutional infrastructure to develop and adopt a specific technology (Markard et al. 2012). To complement the focus on structure, functions that describe what is happening in the TIS can be analysed (Bergek et al. 2008). These functions are intermediate variables situated between structural elements and system performance (Jacobsson and Bergek 2011). In particular, TIS analysis seeks to identify so-called system weaknesses, such as deficient networks or ill-functioning markets, that prohibit further developing the system. The conceptual nature and roots of these weaknesses, including the link to appropriate policy interventions, constitute the focus of the present article.

In new and emerging TISs, different system weaknesses may be common and could seriously hamper further developing the TIS. Examples include deficient coordination between ministries (which undercuts the function of resource mobilization), weak industrial participation (which hampers the knowledge development and diffusion function), or alternative (competing) uses of raw materials (which prohibit market formation processes) (Wieczorek and Hekkert 2012). In fact, addressing system weaknesses may be particularly challenging in advancing sustainable technologies, especially because incumbent (and less sustainable) technologies typically are well supported by rival sociotechnical regimes. Because knowledge accumulation processes tend to be sector-specific (Acemoglu et al. 2012), failures to address important system weaknesses may imply path-dependency, technological lock-in, and thus a lack of regenerating knowledge.

The key proposition of the present article is that the conceptual roots of system weaknesses must be better understood. ${ }^{1}$ Traditional TIS literature assumed that weaknesses reside in structural elements (Bergek et al. 2008). Recent TIS studies have focused on weaknesses related to (or residing in) the functions of the TIS although the two are related as when structural causes can be spotted by highlighting functional weaknesses (Jacobsson and Bergek 2011; Suurs and Hekkert 2009).

However, both older and more recent TIS studies have focused mainly on the question of where these weaknesses reside, have provided examples of what they are (Klein-Woolthuis et al. 2005; Wieczorek and Hekkert 2012), and then discussed what needs to be done to address them. The conceptual roots of system weaknesses is in this way downplayed and/or remains tacit in the analysis. The relationship between these weaknesses and the rationale for policy interventions therefore lacks clear theoretical underpinnings (e.g. Bleda and del Rio 2013). 
In particular, many prior TIS studies seems to assume that quite a few system weaknesses are rooted in technical-, market- or some other type of uncertainty. This is clearly evident in transition studies and literature on developing sustainable technologies (Jacobsson and Bergek 2011; Meijer et al. 2007; Nelson 1994). This focus on uncertainty, and associated policy responses, is justifiable. Few industrial actors may be willing to assume initial investment risks in the lengthy and uncertain development of a TIS, and venture capitalists will typically be unable to fill this funding void.

However, system weaknesses may have different conceptual roots than uncertainty, which therefore is too narrow to fully understand a diverse set of system weaknesses. By drawing on knowledgebased theory and its emphasis on four knowledge problems (e.g. Zack 2001), we argue that the concepts of complexity, equivocality, and ambiguity could complement the prevailing emphasis on uncertainty and may be particularly helpful for better understanding the conceptual roots of several types of system weaknesses.

Uncertainty, as we use the term, centres on insufficient factual information (Galbraith 1973). Complexity occurs when a system has a large number of parts or components that interact in a nonsimple way (Nickerson and Zenger 2004; Simon 1969; Zack 2001). By contrast, equivocality centres on multiple and divergent interpretations by actors of a task, goal, or situation in the presence of the same information (Weick 1979). Finally, ambiguity means inadequate knowledge that makes it difficult to understand or explain a task, a goal, or a given situation (Zack 2001).

Various system weaknesses may thus have different types of knowledge-based roots, and the problems affecting TIS performance are largely brought about by problems in generating and coordinating knowledge (Bleda and del Rio 2013). This underscores the relevance of a knowledge-based perspective on system weakness roots, however without claiming that all possible system weaknesses necessarily root in knowledge problems.

Our focus on knowledge problems thus complements-rather than substitutes-prior categorizations of system weaknesses (e.g. Klein-Woolthuis et al. 2005; Wieczorek and Hekkert 2012). While these prior categorizations identified different types of system weaknesses (i.e. what they are and where they reside), they remain tacit about the knowledge-based roots. We argue that these knowledgebased roots may be viewed as sensitizing concepts that can be used in parallel with various prior categorizations when trying to better comprehend system weakness in TIS.

To this background, our purpose is to introduce-and argue for-a knowledge-based perspective on system weaknesses in TIS that goes beyond the prevailing focus on uncertainty. In extension, we believe such a conceptualization to be useful for achieving a better match between system weaknesses and policy interventions. For example, Borrás and Edquist (2013) states that innovation policy interventions should build on the causes of problems in the innovation systems, and the design of these should be closely related to key activities in the system. Without a thorough understanding of the conceptual roots of a problem or weakness, there is an apparent danger that policymakers may (1) misconceptualize the weaknesses and thereby try to solve the wrong problem (Mitroff and Featheringham 1974); (2) choose an inappropriate policy response that does not match the core of the specific system weakness; or (3) impose a policy response even though TIS actors could have addressed the weakness themselves without any policy intervention.

These policy pitfalls may be further reinforced because of diversity in actor networks. While such diversity, e.g. in terms of expertise, often is desired for securing the necessary resources for technological development, such as competence and legitimacy (Musiolik et al. 2012), it increases the likelihood that network members will perceive a given system weakness differently, in turn leading to so-called representational gaps (cf. Cronin and Weingart 2007). This may be particularly so because many policy decisions emerge not only from a political administrative hierarchy, but are also formulated and implemented within multilevel actor networks beyond formal hierarchies (Flanagan et al. 2011).

Taken together, the above challenges underscore the need for further conceptual development of system weaknesses. In the words of Jacobsson and Bergek (2011: 46), ' ... the question remains how to identify the precise system weaknesses that should be tackled by public policy in a given innovation system at any moment in time'. We cannot provide a precise answer to this question; however, by introducing a knowledge-based perspective of system weaknesses roots, matching certain weaknesses and appropriate policy responses can be improved. We thus contribute with micro-level insights to better understand the difficulties in advancing a TIS through the formative phase.

The remainder of the article is organized as follows. The next section presents a literature review of prior TIS studies, followed by a conceptual discussion on the nature of system weaknesses. Section 3 provides details on our case study, whereas Section 4 contains results and analysis. The article concludes with policy implications and advice for improved problem-solving in actor networks. Some important avenues for future research are also outlined.

\section{Theoretical background}

TIS is rooted conceptually in the wider innovation system literature (e.g. Stankiewicz and Carlsson 1991) and evolutionary economics (Nelson and Winter 1982). In particular, TIS has been used as a lens to better understand path-breaking innovations and sustainability transitions, such as in biomass digestion, solar photovoltaic, or wind energy technology, with a particular emphasis on the so-called 'formative phase' of technology development (Chung 2012; Jacobsson and Bergek 2011; Tigabu et al. 2015). This phase is far from linear. Instead, it is characterized by lengthy development periods, substantial technological and market uncertainties, underdeveloped price/ performance ratios, small production volumes of emerging products, a market demand that may be in its infancy, and weak actor networks.

\subsection{System weaknesses in prior TIS studies}

The concept of system weaknesses is at the heart of TIS analysis and has been proposed to be a core concept in innovation system analysis. System weaknesses are related to (or reside in) the functions of a TIS. An analyst can thus search for functional weaknesses that prohibit a system's improved performance (Jacobsson and Bergek 2011). A key example is the empirical categorization of different types of weaknesses that Wieczorek and Hekkert (2012) proposed, i.e. actor, institutional, interaction and infrastructural weaknesses. Actor weaknesses concern the presence or capabilities of actors, whereas institutional weaknesses highlight the presence or quality of the institutional set up. Interaction weaknesses concern the presence or quality of interactions, and infrastructural weaknesses the presence or quality of the infrastructure (see also Klein-Woolthuis et al. (2005) for a related categorization).

Searching the Scopus database on 'technological innovation system' in the title, abstract, and keywords yielded more than 3700 
counts over the past decade. While some of these may be less relevant, TIS has been used extensively as a framework for analysing sustainability transitions and the emergence of path-breaking technologies (Markard et al. 2012). This research is vibrant and diverse, and it is beyond the scope of the present study to review it in full. However, a couple of remarks apply. First, the TIS framework has been used in a multitude of countries by researchers on all continents. Second, it has been applied to a variety of technological fields, such as biomass digestion, natural gas, hydrogen fuel, mini-grids, and off-shore wind power (Andreasen and Sovacool 2015; Blum et al. 2015a; Negro et al. 2007; Reichardt et al. 2016; Suurs et al. 2010). Third, specific system weaknesses identified in prior TIS studies are indeed diverse and vary greatly. Examples include a lack of collaboration among key actors, institutional battles with rival technologies, an absence of diversity in the actor base, lack of skills and capabilities, and the absence of appropriate policy interventions. Table 1, based on the categorization of system weaknesses proposed by Wieczorek and Hekkert (2012), provides a brief summary of ten recently published TIS studies to illustrate this diversity of context, countries, and specific system weaknesses identified.

According to Jacobsson and Bergek (2011), this wide range of system weaknesses in prior research, which displays significant diversity also within categories, is a strength because it informs policymakers of the multitude of factors that could block the growth of a given TIS. However, this variety may also result from insufficient conceptual analysis of their roots, and with a clear emphasis on various uncertainties. Indeed, other knowledge problems have been ignored or at least remained largely tacit in TIS analyses. In fact, in light of the emphasis on knowledge coordination and actors' capabilities in the evolutionary economics literature (e.g. Nelson and Winter 1982; Metcalfe 2005), the limited explicit attention devoted to knowledge problems in TIS is surprising (see also Bleda and del Rio 2013).

Even though not all system weakness can be argued to be rooted in various types of knowledge problems, this article argues and illustrates that many can. Knowledge-based theory therefore contributes with a new-and complementing-perspective to better comprehend various system weaknesses. In other words, prior system weakness classifications should benefit from being examined also from a knowledge-based point of view.

\subsection{Knowledge-based theory to understand system weaknesses in TIS}

Zack (2001) asked a rhetorical question: If managing knowledge is the solution, then what is the problem? He then proposed that the need to manage knowledge is rooted in four distinct but related problems that require processing information or knowledge in different ways: uncertainty, complexity, equivocality, and ambiguity. We argue that this taxonomy is helpful to better understand the conceptual nature of many system weaknesses in TIS.

As was emphasized in the introduction, an 'uncertainty weakness' or problem per se does not exist. Rather, uncertainty is a sensitizing concept that helps describe the nature and the roots of a system weakness and, through subsequent analysis, may guide policy instrument choices. For example, when actors lack complete information about the future prices of green certificates, as in Jacobsson's (2008) study, then that system weakness may have its approximate roots in uncertainty. By contrast, when the roles and the ownership of infrastructure in a TIS are unclear, as Hellsmark and colleagues (2016a) reported, that weakness may be rooted in ambiguity or complexity. Actors do not know with confidence what roles are assumed by which actors, nor can they know which questions to ask, where to find answers, and which actors do what. In addition, the actors in a TIS may not share a common understanding of the technology, thus leading to difficulties in achieving effective collaboration (e.g. Metcalfe 2005). For this reason, system weaknesses such as lack of entrepreneurial activities and collaboration among actors, as Negro et al. (2007) reported, may relate to an uncertain institutional environment, but may also result from a lack of common understanding (i.e. equivocality).

Uncertainty is defined as the difference between the information available and the information needed to complete a task. According to information processing theory, information processing should be matched with specific tasks to reduce information gaps (Galbraith 1973). Different levels or degrees of uncertainty may exist, but the interpretive context is always assumed to be well defined and known (Zack 2001). Uncertainty is at the core of prior TIS analysis. In particular, many prior TIS studies have assumed that quite a few system weaknesses are rooted in technical-, market- or some other type of uncertainty. This is clearly evident in transition studies and literature on developing sustainable technologies. For example, it is stated that developing a TIS is a process of reconfiguration as the components co-evolve in a process marked with great uncertainty (Jacobsson and Bergek 2011; Nelson 1994; Meijer et al. 2007). In a similar vein, 'A TIS can evolve only if there are actors that explore and exploit new opportunities by conducting experiments, delving into risky and uncertain markets and technologies ...' and ' ... large technical uncertainties, combined with large market risks, make it unlikely that entrepreneurial experimentation will be strengthened without policy intervention' (Jacobsson and Bergek 2011: 48).

Research also shows that actors frequently underestimate the length and uncertainties in this formative phase, where uncertainty may concern institutional, market, organizational, and/or technical factors (e.g. Bergek et al. 2008; Schot and Geels 2008; Hellsmark et al. 2016b). Uncertainty thus centres on a lack of factual information about the current and future states of a TIS. Acquiring more information about the uncertainty, therefore, can reduce it. Alternatively, uncertainty can be better tolerated by using existing situational knowledge, resources, and capabilities (Zack 2001). In the context of evolving TISs, pilot and demonstration plants may play a particularly critical role in reducing, for example, technical uncertainty through experiments that enhance different types of learning processes (Hellsmark et al. 2016 b).

Complexity occurs when a large number of components interact in a non-simple way (Simon 1969). Complex situations are not vague. Instead, they may be clear and fully predictable, but often cause a large variety of elements and relationships that may be too complex to easily comprehend (Zack 2001).

Complexity is at the heart of innovation system research. For example, Malerba (1996: 22) stated that policies may fail because of '... governments' inability to manage complex networks'. Similarly, 'Socio-technical approaches refrain from simple policy recipes, because they highlight co-evolution, multi-dimensionality, complexity and multi-actor processes' (Geels et al. 2008: 4-5). These two studies underscore the importance of complexity as a conceptual basis for system weaknesses.

The degree to which a problem (or weakness) is complex may hint at the appropriate response when searching for a solution. Decomposable problems (a problem that can be subdivided into sub-problems) may benefit from directional search, whereas a non- 
Table 1. A sample of system weaknesses identified in prior TIS studies; categorization according to Wieczorek and Hekkert (2012).

\begin{tabular}{|c|c|c|c|c|c|}
\hline $\begin{array}{l}\text { Authors and } \\
\text { year }\end{array}$ & Publication outlet & Type of TIS & Country or region & $\begin{array}{l}\text { Examples of key system weaknesses } \\
\text { identified }\end{array}$ & $\begin{array}{l}\text { Types of system } \\
\text { weakness }\end{array}$ \\
\hline $\begin{array}{l}\text { Suurs et al. } \\
\quad(2010)\end{array}$ & Energy Policy & $\begin{array}{l}\text { Automotive natural } \\
\text { gas technology }\end{array}$ & The Netherlands & $\begin{array}{l}\text { Low priority of environmental issues, liber- } \\
\text { alization policies in energy sector, disap- } \\
\text { pointing technoeconomic outcomes, } \\
\text { narrow actor base }\end{array}$ & $\begin{array}{l}\text { Institutional and } \\
\text { Actor }\end{array}$ \\
\hline $\begin{array}{l}\text { Andreasen and } \\
\text { Sovacool } \\
(2015)\end{array}$ & $\begin{array}{l}\text { Journal of Cleaner } \\
\quad \text { Production }\end{array}$ & Hydrogen fuel & $\begin{array}{l}\text { Denmark and } \\
\text { United States }\end{array}$ & $\begin{array}{l}\text { Lack of supporting physical infrastructure } \\
\text { (in both countries) }\end{array}$ & Infrastructural \\
\hline $\begin{array}{l}\text { Vasseur et al. } \\
\text { (2013) }\end{array}$ & $\begin{array}{l}\text { Journal of Cleaner } \\
\quad \text { Production }\end{array}$ & $\begin{array}{l}\text { Photovoltaic } \\
\text { technology }\end{array}$ & $\begin{array}{l}\text { The Netherlands } \\
\text { (Japan as con- } \\
\text { trasting case) }\end{array}$ & $\begin{array}{l}\text { Lack of expertise among actors, feedback } \\
\text { from practice to policy and research is } \\
\text { missing, weak political network, weak } \\
\text { 'starting positions', i.e. for resources and } \\
\text { capabilities of Dutch companies }\end{array}$ & $\begin{array}{l}\text { Actor, Interactional } \\
\text { and Institutional }\end{array}$ \\
\hline $\begin{array}{l}\text { Köhler et al. } \\
\text { (2013) }\end{array}$ & $\begin{array}{l}\text { Journal of Cleaner } \\
\text { Production }\end{array}$ & Low carbon cars & Europe & $\begin{array}{l}\text { Technological 'lock-in’, market formation } \\
\text { for low-carbon cars too weak }\end{array}$ & Institutional \\
\hline $\begin{array}{l}\text { Hellsmark et al. } \\
\text { (2016a) }\end{array}$ & $\begin{array}{l}\text { Journal of Cleaner } \\
\quad \text { Production }\end{array}$ & $\begin{array}{l}\text { Biorefinery } \\
\text { development }\end{array}$ & Sweden & $\begin{array}{l}\text { Lack of policy instruments in the niche mar- } \\
\text { ket and commercial growth phases, Weak } \\
\text { coordination (e.g., between ministries and } \\
\text { agencies), weak industrial participation } \\
\text { and absorptive capacity, unclear roles and } \\
\text { ownership of research infrastructure, } \\
\text { alternative uses of raw materials }\end{array}$ & $\begin{array}{l}\text { Institutional, } \\
\text { Interactional, Actor } \\
\text { and Infrastructure }\end{array}$ \\
\hline $\begin{array}{r}\text { Blum et al. } \\
\text { (2015b) }\end{array}$ & $\begin{array}{l}\text { Technological } \\
\text { Forecasting \& } \\
\text { Social Change }\end{array}$ & Mini-grids & Laos & $\begin{array}{l}\text { Institutional mismatches within and across } \\
\text { geographical levels, hampered flows of } \\
\text { resources across levels (in addition to indi- } \\
\text { vidual bottlenecks) }\end{array}$ & $\begin{array}{l}\text { Institutional and } \\
\text { Interactional }\end{array}$ \\
\hline $\begin{array}{l}\text { Reichardt } \\
\text { et al. (2016) }\end{array}$ & $\begin{array}{l}\text { Technological } \\
\text { Forecasting \& } \\
\text { Social Change }\end{array}$ & Offshore wind & Germany & $\begin{array}{l}\text { Lack of regulations for handling offshore } \\
\text { wind permission requests, technical uncer- } \\
\text { tainties, lack of financial capital (among } \\
\text { other things) }\end{array}$ & Institutional \\
\hline $\begin{array}{l}\text { Hudson et al. } \\
\quad(2011)\end{array}$ & $\begin{array}{l}\text { Technology Analysis } \\
\text { \& Strategic } \\
\text { Management }\end{array}$ & Micro-CHP & United Kingdom & $\begin{array}{l}\text { Current strengths incapable of moving tech- } \\
\text { nology beyond niche market phase, lack } \\
\text { of strong advocacy groups to convince } \\
\text { policy and investment groups }\end{array}$ & $\begin{array}{l}\text { Actor and } \\
\text { Institutional }\end{array}$ \\
\hline Palm (2015) & $\begin{array}{l}\text { Environmental } \\
\quad \text { Innovation and } \\
\text { Societal Transitions }\end{array}$ & $\begin{array}{l}\text { Building-sited solar } \\
\text { photovoltaic }\end{array}$ & Sweden & $\begin{array}{l}\text { Poor design of subsidies, which puts a cap } \\
\text { on market development }\end{array}$ & Institutional \\
\hline $\begin{array}{l}\text { Tigabu et al. } \\
\text { (2015) }\end{array}$ & $\begin{array}{l}\text { Science and Public } \\
\quad \text { Policy }\end{array}$ & Biomass digestion & Rwanda and Kenya & $\begin{array}{l}\text { A number of weaknesses identified for all } \\
\text { functions but guidance of search. For } \\
\text { example, Lack of supporting infrastruc- } \\
\text { ture, No support for entrepreneurial activ- } \\
\text { ities and resource limitation (both } \\
\text { financial and human) }\end{array}$ & $\begin{array}{l}\text { Infrastructural and } \\
\text { Institutional }\end{array}$ \\
\hline
\end{tabular}

decomposable problem (problems characterized by great difficulties in breaking them down into smaller parts) may benefit from heuristic search (Nickerson and Zenger 2004).

Equivocality refers to multiple clear but conflicting interpretations of a goal, situation, or task (Eriksson et al. 2016; Weick 1979). It is a defining characteristic of innovation and technology development, because these activities imply creating new knowledge or coordinating existing knowledge and resources in new ways (Frishammar et al. 2011). Equivocality may be a particular challenge in inter-organizational collaboration-such as among the actors in TISs-because of differences in interests and frames of references (Cronin and Weingart 2007). Equivocality may also arise when roles and responsibilities are vague or when disparate political interests allow room for different interpretations (Zack 2001), which may occur when a TIS is in its formative phase (Hellsmark et al. 2016 b). Equivocality often results in time delays, conflicts, and difficulties in coordinating activities across network actors. Equivocality may also strain development even when conflicts do not materialize, because it leads to significantly increased transaction costs (Eriksson et al. 2016). However, this type of knowledge problem may also improve recombining knowledge due to the existence of competing interpretations (Fleming 2001).

Equivocality has not been studied extensively in the context of TIS. However, 'The TIS function "Influence on the direction of search" has much to do with institutional factors, such as incentive structures, cognitive frames and expectations ....' (Jacobsson and Bergek 2011: 49). These authors thus implicitly acknowledged the potential influence of equivocality, that is, cognitive frames may differ among diverse actors (see also the discussion in e.g. Carlsson et al. (2002) on the cognitive dimension of technological systems). Equivocality is also expressed in Metcalfe's (2005) assertion that the knowledge embodied in new technology may not be correlated 
across individual agents. Equivocality may be resolved by exchanging rich information and knowledge to better understand divergence in opinions and positions, for example, through rich media channels (Daft and Lengel 1986). These may allow exchanging subjective interpretations, forming consensus, and enacting shared understanding (Frishammar et al. 2011).

Ambiguity manifests as an inability to interpret something. As with uncertainty and equivocality, ambiguity can be experienced on different levels. Low levels of ambiguity may signal insufficient interpretative knowledge or TIS actors making inappropriate interpretations, whereas high levels signal a complete lack of interpretative knowledge. In the latter case, events may be so unfamiliar that it becomes impossible to estimate what is important and what is not. In the words of Zack (2001: 6): 'If uncertainty represents not having answers, and complexity represents difficulty in finding them, then ambiguity represents not even being able to formulate the questions'. To the best of our knowledge, ambiguity has not been investigated to date in the context of innovation system weaknesses. Ambiguity can be resolved by reframing a situation or problem into something meaningful, by acquiring contextual knowledge from others, or through learning and experience (Zack 2001).

We believe the taxonomy of uncertainty, complexity, equivocality, and ambiguity is helpful to better understand the conceptual nature of many system weaknesses in TIS. By extension, the taxonomy may also help match system weaknesses with appropriate policy responses. It should also be emphasized that the proposed taxonomy goes beyond simply addressing cognitive problems, i.e. problems associated with improving the understanding of a situation or reaching unified interpretations. Some of the concepts certainly have a cognitive dimensions (e.g. equivocality), but the four knowledge problems addressed in Zack (2001) may also include a lack of coordination of knowledge (e.g. due to path dependencies) and/or a need to invest in new joint knowledge creation to reduce uncertainty and/or complexity. The taxonomy thus goes beyond how actors understand or interpret knowledge, and will therefore shed light on a much broader set of issues.

In prior TIS studies, uncertainty has been the predominant conceptual ground for addressing system weaknesses. Complexity has also been discussed extensively, although mainly as a characteristic of innovation systems and policy formulation processes, and less so in relation to system weaknesses per se. Equivocality is clearly less studied, and ambiguity is, perhaps, unstudied. Complexity and uncertainty may be more real and tangible, whereas ambiguity and equivocality have signs of being socially constructed and centred in actor perceptions of reality. Nevertheless, they may all bear implications for policy intervention choices but also for improved problem-solving in the absence of policy intervention. The next section presents our case study and methods on which we base this discussion.

\section{Methods}

The present article draws on data related to two separate but complementary evolving platform technologies that constitute the Swedish biorefinery TIS: thermochemical and biochemical conversion of lignocellulosic biomass. Both of these platform technologies have received significant public financial support over the past decades to develop so-called future biorefineries. This TIS is now in the formative phase of technology development, with pilot- and demonstration plants as the critical infrastructure needed to advance technology (Hellsmark et al. 2016 b).
Multiple data sources were used in the analysis. The main data source was 27 interviews conducted between 2008 and 2015, each lasting about an hour and a half on average. Of these 27 interviews, 15 were recorded, transcribed, and used to generate the quotes used in this article. Table 2 includes details about the sample. The remaining interviews were used to develop a better contextual understanding of the types of problems and challenges the different actors of the TIS faced. The fact that interviews were conducted over a significant timespan allowed us to develop a longitudinal perspective of the field and the challenges the actors faced.

The interviews were conducted across a wide range of TIS actors, including owners of technical infrastructure such as pilotand demonstration plants, research institutions, local municipalities, governmental agencies, industrial firms, and intermediary organizations. The sample thus represents a cross-section of regional and national policymakers, engineers, managers, and academics. These interviews focused on barriers to and drivers of developing the Swedish biorefinery industry, roles, and dynamics of the actors, as well as the role of pilot and demonstration plants and other infrastructure for progressing each respective platform. Interviews were complemented with secondary data including market and research statistics and a full-day workshop with 43 stakeholders with whom the strengths and weaknesses of the biorefinery TIS functions were discussed extensively.

Interviews, secondary data, and the workshop all addressed system weaknesses, but when it started, the empirical study was not designed to understand the underlying conceptual nature of these weaknesses. For example, the majority of interviews were conducted to better understand system weaknesses and strengths per se and how these relate to the various functions of the TIS. Some of the more recent interviews, however, deliberately focused on roles, knowledge management issues, and the conceptual foundations of system weaknesses.

Our approach to data analysis was deductive. The concepts of uncertainty, complexity, equivocality, and ambiguity helped focus the analysis. Again, we used these as 'sensitizing concepts' to guide the data analysis. According to Blumer (1954), sensitizing concepts suggest directions along which to look for patterns in data. A sensitizing concept is thus an interpretative device that can inform the overall research problem (in our case, a better understanding of the conceptual nature of certain system weaknesses). Table 3 defines the four sensitizing concepts along with our operationalization.

In applying these sensitizing concepts, we performed a thematic analysis of the data in three steps. First, we listened to the taped interviews and re-read transcripts, notes, and workshop materials to absorb a general understanding of system weaknesses in the data, what they were, and how respondents talked about them. Second, we generated initial codes by documenting preliminary patterns. In practice, this meant creating lists of quotes and examples of system weakness issues under each of the four sensitizing concepts. That is, we worked to understand which weaknesses were rooted in which sensitizing concept and if/how such links could be established. Third, we reviewed these preliminary lists to thoroughly analyse whether the quotes accurately referred to either one or several of the four sensitizing concepts.

\section{Analysis and results}

Our empirical analysis highlights examples and illustrations of system weaknesses rooted in all four sensitizing concepts-uncertainty, complexity, equivocality, and ambiguity. Key quotes illustrating 
Table 2. Respondents for the empirical study.

\begin{tabular}{|c|c|c|c|}
\hline Date & Organization & Role in developing TIS & Transcribed and coded \\
\hline 16 January 2008 & Göteborg Energy & $\begin{array}{l}\text { Representative of Göteborg Energi and the early development } \\
\text { of the project GoBiGas. }\end{array}$ & No \\
\hline 3 December 2008 & Chemrec & $\begin{array}{l}\text { Former CEO and representative of Chermec's earlier } \\
\text { development }\end{array}$ & No \\
\hline 7 January 2009 & Volvo AB & $\begin{array}{l}\text { Representatives of Volvo Technology and expert on biofuels } \\
\text { and fuel standards }\end{array}$ & No \\
\hline 30 January 2012 & Chalmers University of Technology & $\begin{array}{l}\text { Professor in the Department of Energy Technology at } \\
\text { Chalmers and representative of the current development of } \\
\text { fluidized bed technology }\end{array}$ & No \\
\hline 14 February 2012 & Chalmers University of Technology & $\begin{array}{l}\text { Professor Emeritus in the Department of Energy Technology at } \\
\text { Chalmers and representative of the early development of flu- } \\
\text { idized bed technology }\end{array}$ & No \\
\hline 22 February 2012 & Göteborg Energy & CEO of GoBiGas & No \\
\hline 8 May 2013 & Luleå University of Technology & $\begin{array}{l}\text { Professor at Luleå University and representative of the develop- } \\
\text { ment of black liquour gasification }\end{array}$ & No \\
\hline 19 August 2013 & SP Technical Research Institute & $\begin{array}{l}\text { Manager of the Energy business area at the technical research } \\
\text { institute SP }\end{array}$ & Yes \\
\hline 23 August 2013 & SP Processum & Director of cluster organisation, investing in R\&D & Yes \\
\hline 23 August 2013 & Lindab & $\begin{array}{l}\text { Former CTO at the technology development company Sekab, } \\
\text { representing early development }\end{array}$ & Yes \\
\hline 23 August 2013 & SP Technical Research Institute & $\begin{array}{l}\text { Senior research advisor responsible for the development at a } \\
\text { demonstration plant operated by SP }\end{array}$ & Yes \\
\hline 26 August 2013 & Domsjö Aditya Birla & $\begin{array}{l}\text { Head of innovation and development of new products at } \\
\text { Domsjö, a major producer for dissolving cellulose }\end{array}$ & Yes \\
\hline 26 August 2013 & More Research & CEO of the research consultancy firm MoRe & Yes \\
\hline 27 August 2013 & Umeå University & $\begin{array}{l}\text { University professor, representative of the company Bioendev } \\
\text { and the development of torrefaction }\end{array}$ & Yes \\
\hline 27 August 2013 & SEKAB & $\begin{array}{l}\text { Manager and representative of the current development of } \\
\text { SEKAB }\end{array}$ & Yes \\
\hline 28 August 2013 & Umeå University & $\begin{array}{l}\text { Professor of Chemistry and representative of the research on } \\
\text { biochemical conversion processes }\end{array}$ & Yes \\
\hline 27 September 2013 & Luleå University of Technology & $\begin{array}{l}\text { Principal and formal owner of large infrastructure for biochem- } \\
\text { ical and thermochemical conversion processes }\end{array}$ & Yes \\
\hline 11 March 2014 & Business Region Göteborg & $\begin{array}{l}\text { Representative of the chemistry cluster hosted by Business } \\
\text { Region Göteborg }\end{array}$ & No \\
\hline 14 April 2014 & Innventia & CTO at the research institute Innventia & No \\
\hline 14 April 2014 & Swedish Forest Industries Federation & Director of the Swedish Forest Industries Federation & No \\
\hline 2 May 2014 & Chemrec & CEO and representative of the company's current development & No \\
\hline 12 May 2014 & Akzo Nobel & $\begin{array}{l}\text { Representative of chemical company Akzo Nobel in } \\
\text { Stenungsund }\end{array}$ & No \\
\hline 11 June 2015 & ETC & $\begin{array}{l}\text { Director of a research institute developing thermochemical } \\
\text { conversion processes }\end{array}$ & Yes \\
\hline 10 September 2015 & Chalmers University of Technology & $\begin{array}{l}\text { University professor and representative of the current develop- } \\
\text { ment of indirect gasification }\end{array}$ & Yes \\
\hline 8 October 2015 & Göteborg Energy & $\begin{array}{l}\text { Head of operations at large-scale demonstration plants for } \\
\text { advanced fuels }\end{array}$ & Yes \\
\hline 8 October 2015 & Chalmers University of Technology & $\begin{array}{l}\text { University Professor and representative of the early develop- } \\
\text { ment of lignoboost technology }\end{array}$ & Yes \\
\hline 15 October 2015 & Innventia & $\begin{array}{l}\text { Responsible for developing the lignoboost technology and a } \\
\text { large demonstration facility }\end{array}$ & Yes \\
\hline
\end{tabular}

these were incorporated into the main text, whereas representative quotes were tabulated for each sensitizing concept.

\subsection{System weaknesses rooted in uncertainty}

Similar to many other TIS studies, we found multiple examples of system weaknesses rooted in uncertainty. In particular, our analysis highlighted (1) technical risks and deficient competencies available to pursue new technological opportunities; (2) the political risks associated with future investments in infrastructure because of unstable framework conditions; (3) market risks, for example, price risks of key resources due to fluctuating oil prices, as well as deficient knowledge about future customers and their preferences/willingness to pay; (4) deficient knowledge regarding European Union (EU) funding rules and regulations, for example, NER300 support to demonstration plants; (5) shady principles for risk-sharing between different actors; and (6) deficient knowledge regarding decision and application processes and the associated cost of delays.

Those who are among the first actors to invest in a new technology face great uncertainties in constructing a first-of-its-kind facility, as well as market uncertainties limiting the foreseen upside (in most 
Table 3. Four knowledge problems as sensitizing concepts: Definitions and operationalizations.

\begin{tabular}{|c|c|c|}
\hline Sensitizing concept & Definition & Operationalization: What we looked for in the data \\
\hline Uncertainty & $\begin{array}{l}\text { The difference between the information } \\
\text { available and the information needed to } \\
\text { solve a task (Galbraith 1973) }\end{array}$ & $\begin{array}{l}\text { * Different types of risks, for example, technical-, market-, organiza- } \\
\text { tional-, or institutional risks } \\
\text { " Insufficient information or facts about current and future states, } \\
\text { goals, situations, or tasks in or around the TIS }\end{array}$ \\
\hline Equivocality & $\begin{array}{l}\text { Multiple, clear meanings for, or interpreta- } \\
\text { tions of, the same thing (Weick 1979) }\end{array}$ & $\begin{array}{l}\text { When two respondents in two different interviews arrive at different } \\
\text { conclusions based on the same factual information } \\
\text { * When one respondent talks about erroneous conclusions drawn by } \\
\text { another respondent } \\
\text { * Different interpretations of specific goals, situations, or tasks }\end{array}$ \\
\hline Ambiguity & $\begin{array}{l}\text { Inadequate knowledge (patterns/concepts) } \\
\text { about, no explanation for, or understand- } \\
\text { ing of a goal, situation, or task (Zack } \\
\text { 2001) }\end{array}$ & $\begin{array}{l}\text { * Lack of interpretative knowledge, for example, when events or situa- } \\
\text { tions encountered were experienced as completely new by TIS actors } \\
\text { * When respondents articulated that they did not know what questions } \\
\text { to ask to get the answers they want }\end{array}$ \\
\hline Complexity & $\begin{array}{l}\text { A large number of parts that interact in a } \\
\text { non-simple way (Simon 1969; Nickerson } \\
\text { and Zenger 2004). }\end{array}$ & $\begin{array}{l}\text { "When analysis in many steps is required } \\
\text { "When respondents talk about a multitude of steps and factors affect- } \\
\text { ing system performance } \\
\text { "When respondents talked about "simplifying" problems by breaking } \\
\text { them into smaller parts }\end{array}$ \\
\hline
\end{tabular}

cases, the market is non-existent or very small, and knowledge is lacking regarding potential customers). As one respondent stated:

Of course, when someone takes this step [scaling up to industrial scale], someone will take a blow. Always. Or, not always, but usually. You see, when you scale something up to industrial scale, you have somewhere miscalculated something. The one who takes the first step must take these miscalculations. So, the upside has to be pretty big, especially in a capital intensive and conservative industry like the forestry industry.

Furthermore, uncertainty not only concerns domain-specific technical knowledge, but may also centre on procedural knowledge. In large technology development projects such as these, many diverse actors each bring a small piece of knowledge to the table, but no single actor necessarily wants to provide guarantees or take overall responsibility when all individual pieces are put together. Therefore, if experiences and learning from demonstration and firstof-its-kind industrial scale plants are not appropriately shared, the potential to reduce the technical uncertainties associated with technology development will be constrained.

Although demonstration plants may be instrumental in producing the knowledge required and reducing technical problems and uncertainties, the empirical analysis clearly indicated that uncertainties related to the market in the form of volatile and unbeneficial fossil prices taxed the incentives to take on the role as a first mover. This was further reinforced by the fact that many actors perceived the political and wider institutional uncertainties as high. Almost all respondents touched on this theme more or less directly and voiced concerns about the absence of information regarding future conditions (both for the near- and long-term future). A manager at a technology development company stated:

It's like a wet blanket over this; no one wants to do anything due to the state aid rules on fuels, for example. No one wants to invest a billion and risk to have a decision, some tax or a levy, that sinks it. There are no long-term rules.

We also found examples of some actors lacking sufficient knowledge regarding EU funding rules and the administrative processes associated with large public funding. When not managed, this lack of knowledge caused indecision and time delays, which in turn hampered development in multiple ways. For example, lack of knowledge can lead to long-term uncertainties regarding access to needed skills and expertise through loss of experienced personnel (when they move abroad, to another region, or are internally reassigned to 'hot' projects). Several of the respondents expressed this fear.

Finally, the empirical materials indicated that with time passing and the biorefinery technologies being (rather successfully) demonstrated in pilot and demonstration plants, technical risks were less emphasized by the respondents over time. This may be expected as more knowledge about the emerging technology is accumulated. However, the political risks with future investments in infrastructure went the other direction and was increasingly emphasized in the later interviews because of unstable and uncertain framework conditions. One contributing factor to this was that one proposed national policy programme failed to get approval from the EU, which clearly weakened the domestic biorefinery TIS as much needed deployment policies were never implemented.

Table 4 gives an overview and some examples of system weaknesses that were rooted in uncertainty.

\subsection{System weaknesses rooted in complexity}

We observed three types of system weaknesses rooted in complexity: (1) complexity in emergent value chain(s) due to multiple options for raw material(s), conversion process(es), product(s), and byproduct utilization; (2) complexity stemming from multiple options for the design of business models; and (3); complexity in organizing and managing the research infrastructure.

Complexity in emergent value chains stemmed from the overall complexity of biorefinery technologies and systems. Biorefinery technology can be used to produce many different products based on a variety of bio-based feedstock, including agricultural-, forestbased-, and other waste streams (oils, fats, etc.). Products can be bulk or high-value, and platform products produced can be used for different purposes, including the chemical process industry and for producing fuel or electricity. Here, the complexity lies in identifying the most profitable, or for other reasons most preferred, set of 
Table 4. Quotes regarding system weaknesses that were rooted in uncertainty.

Representative quotes from transcribed interviews regarding system weaknesses that rooted in uncertainty

'Yes, it can be changed any time altogether. It is to say state-of-the-art today, but may be completely different in 10 years'. [Respondent discussed the efficiency of converting raw material into different products for the technology in focus and how it can be expected to be evolved in the future.]

'What you hear from the companies acting in the field is uncertainty about whether there will be support for renewable fuels if you look maybe five years or so ahead. And, it greatly affects their decision to build industrial facilities or not. So, you may say that, yes, the technology is mature. We could build it here, but what about the political and economic situation? This seems to be the part where they [the industry] have the most concerns, which are most uncertain'.

'There's no market .... Then you are back in the quota obligations, with instruments and so on. And, it is so much cheaper to make fossil products today. There needs to be some demand pull. And, the question is when it happens. On the way, such a facility [the demonstration plant] might very well be closed down'.

'This is discussed in each conference: why it does not take off? What are the risks? What are the driving forces? Why does nothing happen? At each conference, we have a session focusing on this. It's the same thing all the time. There is no . . it is not attractive enough. It does not pay to work with new technology, since it is supposed to replace something that is cheaper. What is the premium then? Either oil is too cheap .... The oil is too cheap'.

"It's a little hard to master [the EU project administration riles], especially when it's this kind of indirect financing, counter-financing, what it means, and how to deal with it and when there are several parties involved.... One becomes completely dizzy; it is not easy to know that you are doing right and who should you ask? No, you do not get much help, I think".

'There is a tremendous amount of experience and knowledge residing in the region, and one of the important goals I see is that we perpetuate this. You see, you can mothball the facility, but you cannot mothball skills. If you mothball the plant, the people with skills will get good jobs and buy nice houses somewhere else, and maybe go to other countries. And, we will stand there again and have burned the equivalent of half a billion in this type of research, without having anything more than tin cans. And, they themselves are worth nothing'.

'I think a lot of it ... [lack of development in Sweden compared to Finland] ... is linked to the ruling on the Finnish side to be faster to get in place legislation, as usual. We are still investigating. There are many investigations going on at the same time actually, which makes today's uncertainty greater than ever. Of course no one will invest before the Swedish quota duty investigation is complete or before this investigation on bioproducts within the EU is ready'.

'You need to get hold of [financial] support in some way... Support sounds so damn passive, but some kind of basic .... when you have something good going, they should be able to help without it having to take three years'.

Note: The authors added information in brackets to further clarify some of the quotes.

choices to build a viable value chain. Because the potential value chains are not in place today, the challenge of grasping the full set of potential value chains and their associated economic and environmental potential is amplified by the experienced uncertainty regarding market, policy, and institutional framework as described above. This underscores that some system weaknesses are not mutually exclusive regarding their roots and may reinforce one another. Some of the respondents clearly expressed the potential options as 'too many' to grasp, sometimes expressing the need for guidance from policy or further research to limit the scope of alternatives. The following quote is representative:

Thus, the economy, the overall economics of it all is highly dependent on what you decide to get out of it, DME or methanol or FT-diesel or whatever product you choose to produce in the end. And that it is totally controlled by political decisions.

In addition, weaknesses are rooted in the complexity of comprehending potential synergies with existing value chains and industries. A multitude of options exist for potential integration with existing industries and industrial value chains, but the scale and other differences of the processes (new versus old) make decisions regarding integration complex. The question is which synergies to explore. As one respondent put it:

So when we had agreed to build [this demonstration plant], then the matter was where to place it. Should it be placed in Lund, where the researchers were? In Norrköping, where a grain-based plant was about to be built? Or up here where you had infrastructure and some of the knowledge of the cellulosic raw material?
Value-chain rooted complexity is not all bad news; it also provides opportunities. As many respondents pointed out, when the prerequisites for one product or value chain deteriorate, other potential products can maintain the development and use of research infrastructure, thus pushing technology boundaries forward. These dynamics were visible for one of the biorefinery demonstration plants, which initially focused on demonstration of a technology for production of lignocellulosic ethanol. As time passed and as the interest in ethanol as a vehicle fuel declined, the demonstration plant and the associated technology pathways were partly directed towards high value added chemical building blocks.

The value-chain rooted complexity due to various integration alternatives also provides potential for added values, which can facilitate investments in the new technology even when the investment by itself would not be considered beneficial (e.g., increased production capacity due to debottlenecking of a key process step).

Finally, system weaknesses could also be rooted in complexity regarding the organisation and management of the research infrastructure. The scale of the research infrastructure and the associated investment and high operating costs frequently created an organizational mélange, in which a large number of actors and stakeholders were involved as owners, financers, managers, and so on. Consequently, it was often difficult to identify who was responsible or had mandate over the plant. Our analysis also revealed that, as time passed and the aim and purpose of pilot and demonstration plants evolved, so did the need for organization and management of the research infrastructures, which further exacerbated complexity. Similar complexity was identified for managing the policy area and processes. Because the bioeconomy and industrial biorefineries are cross-sectorial areas with potential to impact multiple parts of 
Table 5. Quotes regarding system weaknesses rooted in complexity.

Representative quotes from transcribed interviews regarding system weaknesses that rooted in complexity

"You've got a raw material that is extremely inhomogeneous. There is the difference between the various logs, the difference between different types of wood, and if you compare a stock and grass .... Then these waste products from corn cobs, it is completely another [material] ... Although the content, there are the same components in them, though, to different degrees, and oriented in different ways. So, [the challenge is] to find a process that generally can take in whatever and still will give you constantly the same thing as output. Again, it is a huge challenge".

"It is rather clear, that if you produce synthesis gas, you can basically produce any product, it's just a matter of economics". [Respondent talking about complexity regarding end-product choices and what to manufacture.]

"Then there are differences, of course, it differs a lot depending on the raw material. Black liquor is not a homogeneous chemical, to put it that way. It depends on what you have inserted in the factory from the beginning".

"There have been so many different initiatives that actually competed with each other, and now [we] have a chance to put them all at the table and analyze LCA, technoeconomic performance, development status.... There will be no sacred truth, but it is anyway a rough picture ....Is it cheaper and better with pyrolysis compared to torrefaction [for entrained flow gasification], or is it about the same so that we can continue to work on both tracks"?

"Their recovery boiler was a bottle neck, and then to extract lignin it is beneficial to relieve the recovery boiler and in that way they could increase their fiber production. . .so it was a good one. So, their motivation to invest was really to increase pulp production, which they have done. They did not really need to sell the lignin to obtain a positive calculation”. [Respondent was illustrating complexity in the production process.]

"Today it's a mishmash. The staff is the employees of [the technology developer] and [the institute] is buying the service of operation from them. The plant is owned by the [company], which in turn is owned by the university holding companies and the [technology developer] by a minority share. They are still the owners. So, today it is a huge mess".

Note: The authors added information in brackets to further clarify some of the quotes.

society, their development is linked to a multitude of policy areas and authorities. It is thus a complex area both for policy to grasp and to govern. To illustrate, one respondent explained:

If you think about it, regarding what policy area it belongs to,... well it is at the intersection between energy policy, economic policy, and environmental policy in a way. This, in turn, provides a multitude of possible authorities who can act.

Table 5 provides quotes and examples of system weaknesses rooted in complexity.

\subsection{System weaknesses rooted in equivocality}

Overall, many informants described system weaknesses that were rooted in equivocality as inherently challenging to address, because they required unifying and aligning perspectives. In our empirical materials, the weaknesses rooted in equivocality centred around divergent interpretations regarding (1) technology and product choices, such as which firm-level processes and products were most desirable to use and develop; (2) what biomass should be used for on an overall level, that is, chemicals or something else?; (3) diverging perceptions regarding which role biorefineries must play for addressing climate change compared to, for example, electromobility and carbon capture storage; (4) organising and managing resources and actors, such as who should take responsibility for what and how resources should be prioritized and; (5) attractiveness of new technology and future business cases.

The empirical analysis showed that the actors' individual interpretations of technological opportunities gave rise to equivocality, rather than merely lack of legitimacy or social capital. One example is that as time passed, costs for renewable electricity production from solar and wind decreased, and battery technology progressed. Combined, these changes made electromobiliy more and more a viable substitute to biofuels for addressing climate change rather than merely a complement, not least in the public debate. According to some of our later interviews, this seems to have increased opinion divergence regarding the role of biorefineries and use of biomass for energy purposes.
It was also clear that actors' individual interpretations were greatly affected by their preconceptions and organizational and regional affiliations. For example, one respondent reflected on reasons why different actors in the biofuel area, which have their interest either from agricultural-based raw material or forest-based raw material, do not interpret the Renewable Energy Directive (RED) in similar ways:

It is a challenge to get industries to agree about what they think is right, for different policy instruments affect the various industries in different ways. Take biofuels; it is a hot potato. For example, how to stimulate biofuel from forest and agricultural land respectively. Here the RED directives discussed in the EU ... will point to the one or the other. It seems difficult to find any kind of neutrality between agricultural land and forest. It is perhaps... one can think that, in Central Europe, the forest is something that is a scarce resource, nice, and used to walk in. While here [in Northern Europe] we see the forest largely as a production resource, because we have so much of it.

These differences in interpretations of what actually constitutes sustainable forestry principles and what the forest should be used for are even more evident in our later interwiews and workshop, reflecting the recent debate regarding the revision of the RED.

Another respondent reflected on the peculiarity of how two different governmental agencies in Sweden, both of which fund demonstration plants, interpret state rules regarding funding levels and project classification rather differently and how these differences in interpretations affect the development of the TIS:

For now the state's accountants pulled the screws quite a bit with the authorities, and just because we're talking in parallel with the Swedish Energy Agency and VINNOVA, their lawyers sitting and scratching his head. How should we interpret this then? VINNOVA, so far, has interpreted it much, much harder than the Swedish Energy Agency. And, it is all about how to classify projects that are in development, how close to the market it is, and so on. These are quite tiresome discussions.

System weaknesses that are rooted in equivocality also stemmed from unclear roles of industrial and public actors and what they 
Table 6. Quotes regarding system weaknesses rooted in equivocality.

Representative quotes from transcribed interviews regarding system weaknesses that rooted in equivocality

"There are many who, so to speak, put forward the opinion that "my biofuels are better than yours"... But it's not different bio-based products that should be set against each other. They're supposed to be set against the fossil ones".

"Well, that is one of the problems, that people do not distinguish the different types of ethanol. There's very good ethanol from an environmental point of view and rather poor ethanol from an environmental point of view. It rarely appears in the more political analysis when people categorically take a position for or against. But, we may see the debate sober a little. I think so".

"The big volumes will be a vehicle fuel. I think". [Compare this quote with the quote below.]

"In the first place, it may not be for [production of] fuel, but it could be an option to take different types of fuels for production through IGCC concepts or something". [Compare this quote with the quote above.]

"Is this really a thing that academics should be doing? How far should we go with an idea towards commercialization? How far should the university tag along? And I heard last week, the most basic scientists they, of course, question this [demonstration unit]. But I do not think so. The greatest task we have is reaching all the way as quickly as possible, before this gap. And we must all ... assume responsibility and comply with at least a piece of the gap".

"Should we have such a business it must be able to live and thrive in the same conditions as the other activities we have at the university? Our task is to do research. Not to do an ancillary [demonstration] business financed by internal funds" [Respondent is referring to industry expectations on the university"s role].

"The problem is if this kind of organization [universities] believes that they should be technology suppliers or add value into a sphere of products. The problem always arises when you are not clear on your role. Many interpret the third task as to start their own new companies and create products. If you have that mindset when you participate in this type of project, it creates incredible problems and lockups".

"The state aid rules are interpreted differently by everyone all the time. So, I'm not surprised, though I think it is a bit strange".

"We would rather make briquettes than pellets. The industry wants pellets today, but I think they will want briquettes going forward".

Note: The authors added the information in brackets to further clarify some of the quotes.

actually should and are allowed to do to promote the new biorefinery technologies. Many of the demonstration plants initially rallied strong support for development, which facilitated construction of the plants, often with municipal resources contributing significant parts of the budget. However, as time passed, clear disagreement about the initiatives was evident in the empirical materials. The debate surrounds whether it is really the role of municipal companies (such as local energy companies owned by municipals) to take on risky and expensive technology development projects, thereby risking taxpayer's money. Similar divergent opinions were found in the empiric material regarding the role of universities and academic researchers, and how much they should be engaged in the technology development and commercialization processes, as well as how the state should allocate public support between basic research and demonstration projects. Table 6 includes representative quotes illustrating the scope of system weaknesses rooted in equivocality as identified in the present study's empirical material.

\subsection{System weaknesses rooting in ambiguity}

To some extent, ambiguity relates to the notion that 'you don't know what you don't know'. As such, system weaknesses rooted in ambiguity was the most difficult to illustrate, as respondents lacked knowledge, concepts, or experience to make interpretations. However, this does not mean ambiguity is not present or that it is not important. The analysis of the empirical material identified two types of system weaknesses rooted in ambiguity: (1) the occurrence of unexpected events that one does not have the experience or framework to manage and (2) improper/inadequate knowledge leading to being unable to analyse the 'right' questions.

Because the biorefinery TIS is about demonstrating technologies for the first time in large scale, the actors are in unexplored territory where ambiguity is indeed expected. Furthermore, because the biorefinery area is a strongly cross-sectorial and multidisciplinary field, the actors' previous academic and industrial experiences do not necessarily mesh with the challenges of the biorefinery TIS, nor need they always match each other. As one respondent put it:

It's probably nothing that was not rebuilt, and yet [the plant] was built by skilled engineers who have built a lot of factories before, and they did it based on their experience. But much of it did not work for this purpose and these processes.

The empirical analysis also indicated that the respondents were aware of ambiguity in the way they expressed the need for experienced and flexible personnel, motivated by the fact that a large part of managing the demonstration plant relates to problem-solving and dealing with unexpected events. In addition, some of the respondents argued that experienced personnel was important, because the customers seldom knew exactly what they wanted to do with the plant or how to make a new technology reach its full potential.

During the interviews, multiple informants argued that one way to manage ambiguity was to open up actor networks to make it easier for knowledge sharing and learning between incumbent and new actors in the system. This was observed to be important especially when actors from different fields (established regimes/ incumbents) were trying to establish a first-of-its-kind demonstration plant for emerging technology jointly with newcomers. It was evident that the actors had different prerequisites, spoke different languages, and at the time, none of them understood the full picture. These conditions caused weaknesses and problems. Comparing earlier interviews with more recent ones, an increasing awareness of the importance of learning and knowledge sharing among actors from different fields was indicated as a means to proactively manage ambiguity.

Lack of interpretive knowledge can also lead to problems with legitimacy and developing social capital when new technology challenges are not fully understood and not managed successfully. If one does not see a problem, it is difficult to try to prevent it, and if one is interpreting the situation based on knowledge of the existing regime, one is not likely to identify problems related to the 
Table 7. Quotes regarding system weaknesses rooted in ambiguity.

Representative quotes from transcribed interviews regarding system weaknesses that rooted in ambiguity

"It's been a huge challenge to put together such a huge project as this, because it is two worlds meeting, and they do not speak the same language. Many of the problems they encountered to reach full load is in the interface between these two deliveries. There was nobody really who had thought [about it] or knew anything Thus, things fell through the cracks".

"This requires experimenters; it takes anywhere between two to three engineers. And, then I talk about engineers, scientists, who know about biotechnology, plan and conduct experiments. For we sell not just experiments. The customer seldom knows exactly how they want to run the plant. So, a big part of the job is experimental design, reporting, evaluation ...."

"One of the crucial issues when running demonstration facilities is staffing; it requires well-trained operators. It requires much more educated, or experienced, operators in a demonstration plant than in a factory, where they train people to do the same thing every day, basically. With slight exaggeration, of course ... But this is not it ... There's no two days that are alike. It's problem-solving and always new stuff [happening] ..."

"There are many researchers working on cellulosic ethanol that do not know about it. But, it is well developed, mainly by Scania. And, yes, even at the graduate level often people have not really kept up with developments. It makes these kinds of ideas come forward-'do not engage in that, deal with this instead'".

"Most of what has been written already [relates to] the step before filtration: the precipitation of lignin. When it came to filtration, there generally was little data, and then it was often a sentence that was, 'It's very difficult to filter.' So, we started with just precipitation and got similar results. Then the next step was to filter it, and then we thought like ?this will be very difficult?. But it went really easily! My first thought was that they've just put out smokescreens, because they did not want someone else to do this. But then the next step when you should wash the filter cake, pouring on water, and pushing it through the filter cake, nothing happened. Not a single drop came out. Then, we realized, okay, it's not filtering that is cumbersome. It is the next step, washing, that is cumbersome".

Note: The authors added information in brackets to further clarify some of the quotes.

new emerging technology. For the biorefinery TIS, one respondent explained:

The biofuel business is very different from our ordinary business. We did not expect that we would be criticized so heavily for buying palm oil, even though it was certified. The public does not ask such questions for crude oil.

These types of challenges, rooted in ambiguity, are not uncommon for the biorefinery TIS. Similarly, there is, for example, the ongoing discussion on how to view so-called first-generation biofuels (grain-based) related to both the food versus the fuel debate and the debate on indirect land use change. When these biofuels first were established on the market, they were viewed as good green investments, but as time has passed, and new knowledge has been gained, their environmental impacts are being increasingly questioned. In the most recent years a similar debate regarding sustainable forestry and the sustainability value of forest based biomass used for energy purposes has emerged, viewed by some as causing ambiguity. In Table 7 , representative quotes from the interviews regarding ambiguity are presented, while Fig. 1 provides a visual overview of the four types of knowledge problems with their subcategories that we have addressed.

\section{Discussion}

The present article has proposed, and argued for, a knowledge-based perspective of system weaknesses in TIS. Knowledge-based theory has allowed us to go beyond system weaknesses rooted in uncertainty, which typically has dominated the TIS literature to date. Complexity, equivocality, and ambiguity may complement this traditional focus on uncertainty and provide implications for both the TIS framework and, by extension, for forming innovation policy.

The present article is exploratory and does not attempt to provide all-encompassing theoretical underpinnings for understanding all possible system weaknesses in TIS. Still, our empirical analysis showcases that these problems exist not only in theory; therefore, our article constitutes one building block for further conceptual analyses of the system weakness concept. It also contributes to a more in-depth understanding of some of the challenges involved in advancing a technological field such as biorefinery development. In this section, the wider policy implications of this knowledgebased perspective, as well as directions for future research are discussed.

\subsection{Policy implications}

The performance of a TIS depends crucially on its actors, their interactions, coordination of knowledge, and the institutional frameworks governing collaborative activities. Many system weaknesses can therefore be understood as factors blocking the process of building agents' capabilities to generate, use and diffuse knowledge or difficulties in coordinating such knowledge (e.g. Bleda and del Rio 2013).

By distinguishing among four knowledge problems, it is possible to arrive at a better understanding of the role that policy may play in supporting the formative phase of a TIS that avoids simplified normative notions about specific policy instrument choices regardless of context (cf. Flanagan and Uyarra 2016).

Below, we address a number of challenges for the policy formulation process, as well as resulting interventions, and provide examples of how these challenges can be managed in the presence of different types of knowledge problems. Some examples of the dynamics of knowledge problems are also provided, although these largely remains a key issue for future research (see also subsection 5.2).

Most TIS studies are biased toward emphasizing the role of uncertainty and initial investment risks, thus building on the notion that private actors often will be unwilling or incapable of internalizing these risks in the absence of policy support. Our empirical analysis provided examples of how key actors (e.g. catalyst producers) have been reluctant to contribute to biorefinery development due to policy and market conditions perceived as too uncertain.

To this background, it has long been acknowledged that combining technology-push policies (e.g. research and development [R\&D] subsidies) and demand-pull policies (e.g. supporting the deployment of technology) is required to stimulate sufficient levels of innovation and progress. Both these policies alter the perceived rate-of-return 


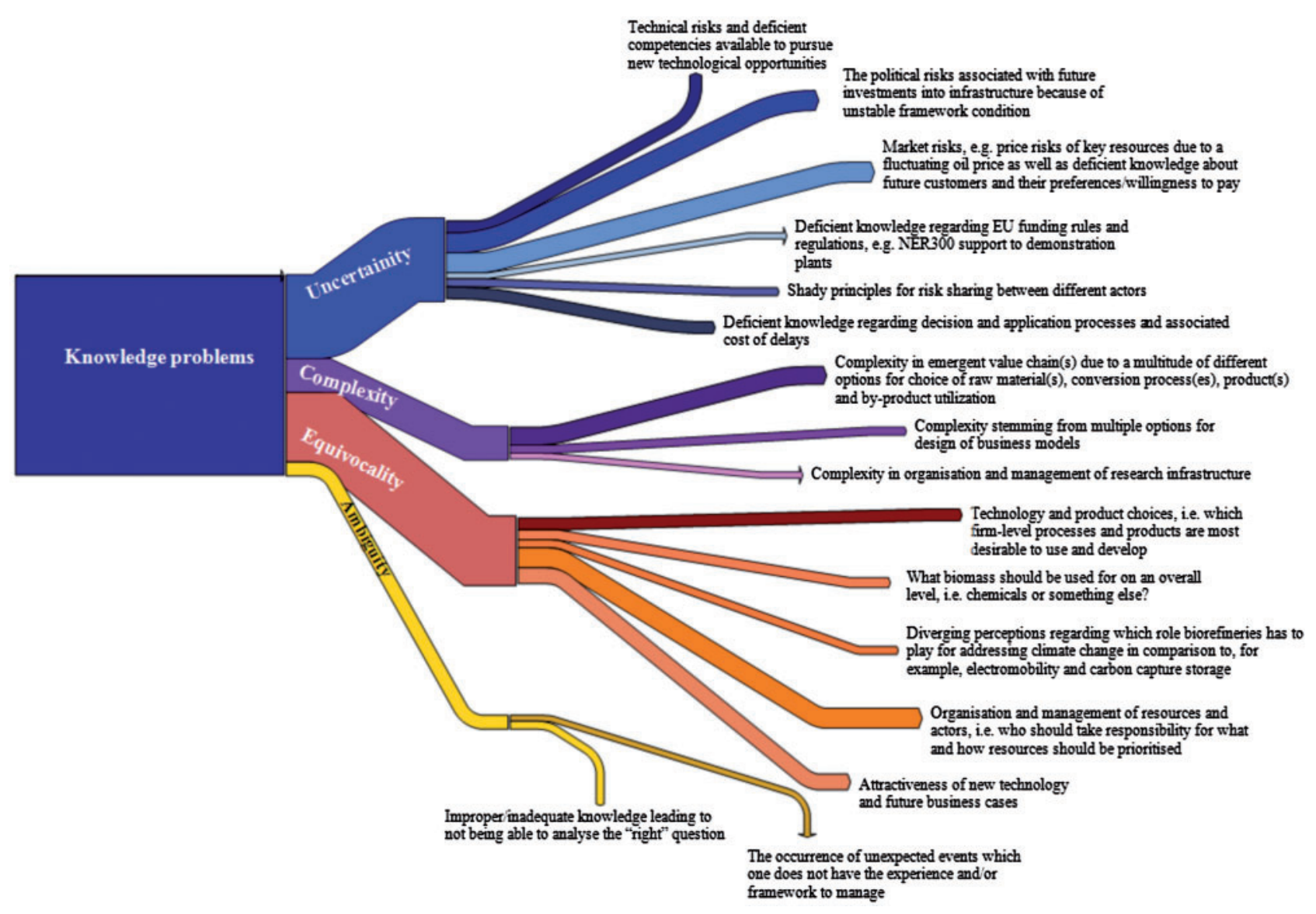

Figure 1. A visual representation of the four knowledge problems, including sub-categories.

(pay-off) on future investments and thus contribute to the necessary economic incentives for key TIS actors to act as first movers. Such policies also create stable opportunities for followers that can benefit from the learning these investments generates as positive externalities (Bergek et al. 2008). Thus, at a general level, there is little controversy about the policy interventions needed to address system weaknesses rooting in technical, market, or institutional uncertainty.

However, acknowledging the presence of other knowledge problems beyond uncertainty requires a more deliberate focus on the coordination of knowledge, that is, on the composition and performance of the actor network and its embedded knowledge, as well as on the collaborative processes taking place within this network over time. Recent innovation policy literature emphasizes that policy concerns different levels of government and it is often created within informal, multi-actor networks beyond formal hierarchies, including interactions at local levels and with regional authorities (e.g. Borrás and Edquist 2013; Flanagan et al. 2011; Rogge and Reichardt 2016).

It is surprising, therefore, that relatively little attention has been devoted to providing a clearer understanding of the roots of system weaknesses, including the lack of entrepreneurial activities, deficient collaboration among actors, and how to govern the evolution of emerging networks (see Musiolik et al. (2012) for an exception). Kern (2015) also calls for more careful TIS studies of the political agency of a diverse set of actors (e.g. not only knowledge-generating firms) and how these help shape the development of the TIS. If the full variety of knowledge problems is not addressed in thinking about policy, there is a risk that many policy responses will be geared towards creating more information (i.e. reducing uncertainty) rather than, for instance, creating shared meaning and understanding (i.e. responses related to ambiguity and equivocality).

Analysing knowledge problems beyond uncertainty, such as equivocality and ambiguity, combined with key lessons from policy network theory (e.g. Klijn 2005), can provide a useful analytical lens through which the relationship between system weaknesses and appropriate policy intervention can be better understood. Specifically, we can benefit from important lessons concerning how actor networks can be managed, that is, so-called network management. Klijn (2005) outlined three main strategies aimed at influencing the collaborative process in an actor network and within given institutional framework conditions (see also Klijn et al. 2010; Newell et al. 2017):

- Activation (deactivation) of actors and resources aims to influence the structure of the network, for example, through engaging new actors, building coalitions, and so on;

- Goal-achieving strategies (e.g. by a network manager) attempt to facilitate goal congruency and goal intertwinement among the involved actors, for example by reformulating the agenda/problem to correspond with the interests of key actors or proposed package deals; and

- Interaction guiding and organizational arrangements include efforts to influence how development is organized, such as adopting the roles of brokers and mediators among actors. 
By linking these strategies to knowledge problems, the risk of adopting policy interventions that do not match the roots of certain system weaknesses can be reduced. Still, this approach acknowledges that a multiplicity of actors-state and non-state, individual and corporate, and so on-typically will be involved in shaping policy (Laranja et al. 2008). This implies that not only can government authorities pursue network management strategies, but other actors do not passively perform functions in a TIS; rather, they play roles (e.g. as mediators, network managers) (see also Mossberg et al. 2018).

Consequently, different types of knowledge problems ought to provide room for different network management strategies in the traditional innovation policy mix. See Table 8. Designing these policy mixes may be particularly important for the sustainable technologies and transitions we have studied, as these centre on disruptive technologies and require policies for wider changes of the sociotechnical system (Kivimaa and Kern 2016). Furthermore, there may be dynamic interdependencies in and between system problems or weaknesses as the technology unfolds, which require adjustments in the policy mix (Reichardt et al. 2016).

For example, system weaknesses rooted in complexity tend to become more profound as the actor network expands, the number of competing designs and value chains increase, and the technology moves closer to the market. As aforementioned, these dynamics may be attributed to a combination of a large number of technology application trajectories and multiple options for synergies with incumbent industries along existing and future value chains. This typically creates difficulties in choosing between discovering overall market opportunities along multiple trajectories on the one hand and targeting particular applications and how to concentrate resources on the other. There may simply be too many options and relationships to consider simultaneously (cf. Zack 2001).

In the case of complexity, activating new actors with greater capacity to decompose complex problems or strengthening existing actors' capacity may constitute an important policy response. For example, system analysts from universities and research institutes may help shed light on the economic and environmental implications of different trajectories using modelling tools. Overall, the typical policy response to increased complexity is to simplify and even limit the choice set (sometimes referred to as a bracketing strategy). This could include several goal-achieving strategies, such as setting clearer goals where some technological pathways may be excluded from further policy support, as well as influencing the ways in which actors perceive the future challenges of the TIS.

Deployment policies that support large-scale generation of new technologies may contribute to narrowing choices by increasing the selection pressure for certain alternatives by, for example, introducing a quota for biofuels or introducing more technology-specific support aimed at advancing its development (Lehmann and Söderholm 2017). Such policies may alter the dynamics of the TIS by affecting knowledge coordination activities and actors' perceptions. Still, simply relying on policy instruments that alter the expected pay-offs may often not be enough. Attempts to reframe the scope of the agenda may need to complement these policies, for example, in terms of climate mitigation, industrial competitiveness, regional development, or any combination of underlying goals.

Moreover, the transition from basic R\&D and knowledge generation through up-scaling and verification may be particularly characterized by equivocality. Indeed, the results from these experiments concern multiple alternative trajectories and development paths, as well as actor networks whose driving forces and interpretations of the results could vary tremendously. Hence, many system weaknesses may have their roots, partly or fully, in equivocality. For example, one successful experiment in a pilot plant may lead to fundamentally different interpretations, such as perspectives as to whether to continue discovering suitable market opportunities by investigating even more applications or instead targeting a particular application and concentrating resources on this. Addressing this type of knowledge coordination problem by improving the rate-ofreturn on risky investments may not provide an adequate (or at least not a sufficient) policy intervention. The underlying problem of diverging interpretations may well remain and it could even become more profound; extended actor networks following due to the less uncertain investment environment could imply a greater risk for conflicts of interest. Moreover, the new policy may in and of itself carry different meanings from actor to actor and may even be reinterpreted over time along with changing perceptions and priorities (Flanagan and Uyarra 2016).

Instead, the typical solution to weaknesses rooted in equivocality includes efforts to unify actors' perceptions and interpretations (Zack 2001). This type of problem is thus not easily addressed by investing in more resources, such as public support for pilot and demonstration plants for additional technical experiments. Rather, it calls for a reflexive policy process in which sensemaking is essential (see also Fogelberg and Sandén 2008). Therefore, an important policy intervention is to facilitate goal congruency and goal intertwinement within the actor network. For example, in the biorefinery field, the latter has often been manifested in efforts to link technology development to regional development goals (e.g., Hellsmark et al. 2016 b). This could be facilitated, in turn, by new organizational arrangements-for example, mediators, initiating boards or joint projects-that help adjust diverging interpretations and assist in making compromise agreements possible.

Weaknesses rooted in ambiguity are characterized by a lack of interpretative knowledge, such as limited understanding of a goal or in encountering a new situation (Zack 2001). This type of knowledge problem may be particularly prevalent in cases in which the new technology depends on active participation of incumbent industries (e.g., the pulp and paper industry in the biorefinery case). These actors have invested in technology-specific human and physical capital, and they have an incentive to direct future innovation activities toward technologies that can make use of these investments. For this reason, they may lack the needed interpretative knowledge to deal with new opportunities because they face underdeveloped absorptive capacity (Hellsmark et al 2016a; Metcalfe 2005).

However, ambiguity is also likely to surface when new actors attempt to advance sustainable technology. In the early stages of TIS development, the focus is often on scientists and engineers attempting to reduce technical uncertainties to verify the technology and permit further up-scaling. However, to progress toward commercialization, the entire sociotechnical system needs to be developed to establish new markets and align institutions (e.g., legal rules, norms), as well as public attitudes. The problem of ambiguity may therefore grow over time.

The simple response to ambiguity problems is clarification, which improves actors' ability to interpret and deal with new situations. From a network management perspective, an important strategy may therefore be to actively involve new actors, remove obstacles for such participation, and help create new organizational arrangements (e.g., boards, projects). Bringing in new actors and facilitating coalition-building broadens the knowledge base and should make it easier to deal with ambiguity. If ambiguity is 
Table 8. Knowledge problems beyond uncertainty and potential policy response.

\begin{tabular}{|c|c|c|}
\hline Knowledge problem & From the case analysis & Potential policy response \\
\hline Complexity & $\begin{array}{l}\text { (1) complexity in emergent value chain(s) due to choice of raw } \\
\text { material(s), conversion process(es), product(s) and by-prod- } \\
\text { uct utilization; (2) complexity stemming from multiple } \\
\text { options for design of business models; and (3) complexity in } \\
\text { organising and managing the research infrastructure. }\end{array}$ & $\begin{array}{l}\text { - Activating actors with greater capacity to decompose com- } \\
\text { plex problems or strengthening existing actors" capacity to } \\
\text { do so } \\
\text { - Limit choices by setting clearer goals or implementing poli- } \\
\text { cies with stronger selection effect. }\end{array}$ \\
\hline Equivocality & $\begin{array}{l}\text { (1) technology and product choices, that is, which firm-level } \\
\text { processes and products are most desirable to use and } \\
\text { develop; (2) what biomass should be used for on an overall } \\
\text { level, that is, chemicals or something else?; (3) diverging per- } \\
\text { ceptions regarding which role biorefineries has to play for } \\
\text { addressing climate change in comparison to, for example, } \\
\text { electromobility and carbon capture storage; (4) organizing } \\
\text { and managing resources and actors, that is, who should take } \\
\text { responsibility for what and how resources should be priori- } \\
\text { tised and; (5) attractiveness of new technology and future } \\
\text { business cases. }\end{array}$ & $\begin{array}{l}\text { - Facilitate goal congruency and goal intertwinement within } \\
\text { the actor network, with the goal of unify actors' perceptions } \\
\text { and interpretations through a 'reflexive policy' process } \\
\text { (stimulating sensemaking is essential). } \\
\text { - This, in turn, could be facilitated by new organizational } \\
\text { arrangements-for example, mediators, the initiation of } \\
\text { boards or joint projects-that facilitate the adjustment of } \\
\text { diverging interpretations and assist in making compromis- } \\
\text { ing agreements possible. }\end{array}$ \\
\hline Ambiguity & $\begin{array}{l}\text { (1) the occurrence of unexpected events that one does not have } \\
\text { the experience and/or framework to manage and (2) } \\
\text { improper/inadequate knowledge leading to not being able to } \\
\text { analyse the "right" question. }\end{array}$ & $\begin{array}{l}\text { Actively involve new actors, remove obstacles for such par- } \\
\text { ticipation, and help create new organizational arrange- } \\
\text { ments (e.g. boards, projects). } \\
\text { Bringing in new actors and facilitate coalition-building } \\
\text { broadens the knowledge base and should make it easier to } \\
\text { deal with ambiguity. }\end{array}$ \\
\hline
\end{tabular}
deal with ambiguity.

misinterpreted as uncertainty, however, and policymakers respond by reducing investment risks (e.g., through deployment policies), learning about institutional and market-related risks may increase, but it may also imply increased ambiguity (and complexity) as technical, economic, and social issues become increasingly intertwined.

Unless key actors take steps to broaden the actor network, interpretative knowledge may remain undeveloped, which may result in a bias toward further optimizing and verifying the old technology and its applications at the expense of increasing efficiency and performance along new value chains. Several types of actors may take on this actoractivating role, but often the involvement of government authorities is important as illustrated by the Swedish Energy Agency's attempts to engage, for example, catalyst providers in the biorefinery TIS.

\subsection{Future research}

We encourage future research on better linking various system weaknesses to particular knowledge problems, but also linking knowledge problems to various TIS functions. Another area for future research is empirical studies on policy formulation in light of various knowledge problems. As aforementioned, these problems may have strong implications for the design of appropriate policy mixes for addressing weaknesses in TIS. Furthermore, the type of weakness may also have a direct impact on the time sequence of activities in implementing policy mixes. For example, if the weakness manifests as unclear ownership of infrastructure, that weakness may be rooted in two or more knowledge problems with different magnitudes. It may have its roots mainly in complexity, but with elements of uncertainty as well. A policy mix must then address both of these problems, perhaps uncertainty first and complexity later, because a hierarchy exists among these problems (Zack 2001).

Another area for future research is improved problem-solving by actor networks without policy interventions, that is, to study how a diverse set of actors in a TIS perceive and act to better manage uncertainty, complexity, equivocality, and ambiguity. It would be interesting to study the effects when one type of problem is mistaken for another, for example, what might be the effects when an equivocal situation is mistaken for an uncertain one? Yet another idea for future research is to pay deliberate attention to the nature of knowledge problems and find better techniques for inferring them. For example, there is a thin line between equivocality and actors having divergent views due to each individual simply having different interests. This situation may affect the choice of what information they seek and interpret. Because the present study was exploratory, these differences were sometimes difficult to bear out, and future research to better discriminate these effects will clearly be valuable.

Finally, our primary contribution has been to introduce, and argue for, the relevance of a knowledge-based perspective for better understanding system weaknesses in TIS. While the empirical case study and policy discussions exemplified some of these dynamics at play, our study did not provide an in-depth assessment of the dynamics of knowledge problems and coordination over time. However, the knowledge-based perspective opens up for future research the opportunity to analyse in depth the dynamics and distributions of knowledge problems and TIS actor perceptions, which is critical to better understand TIS micro-foundations (e.g. how different actors think and act over time).

\section{Note}

1. System weaknesses, systemic problems, system imperfections, bottlenecks, and system failures are approximate synonyms (Wieczorek and Hekkert 2012; Bleda and del Rio 2013). We use the term 'system weaknesses' throughout the present article to avoid confusion resulting from mixing similar terms. We define a weakness as a deviation from a desired set of specific or a range of acceptable conditions resulting in a symptom or a web of symptoms recognized as needing to be addressed (Baer et al. 2013). Our idea of a system weakness is thus similar to that of a 'problem' in strategic management research. 


\section{Acknowledgements}

Financial support from the Swedish Research Council Formas, the Swedish Energy Agency, the Bio4Energy research environment, Vinnova (the 'Forest Chemistry' program), and Chalmers Energy Initiative (CEI) is gratefully acknowledged.

\section{References}

Acemoglu, D., Aghion, P., Bursztyn, L., and Hemous, D. (2012) 'The Environment and Directed Technical Change', American Economic Review, 102: 131-66.

Andreasen, K., and Sovacool, B. (2015) 'Hydrogen Technological Innovation Systems in Practice: Comparing Danish and American Approaches to Fuel Cell Development', Journal of Cleaner Production, 94 (May): 359-68.

Baer, M., Dirks, K., and Nickerson, J. (2013) 'Microfoundations of Strategic Problem Formulation', Strategic Management Journal, 32/2: 197-214.

Bergek, A., Jacobsson, S., Carlsson, B. et al. (2008) 'Analyzing the Functional Dynamics of Technological Innovation Systems: A Scheme of Analysis', Research Policy, 37/3: 407-29.

Bleda, M., and del Rio, P. (2013) 'The Market Failure and the Systemic Failure Rationales in Technological Innovation Systems', Research Policy, 42: 1039-52.

Blum, N. U., Bening, C. R., and Schmidt, T. S. (2015a) 'The Need to Increase the Policy Relevance of the Functional Approach to Technological Innovation Systems (TIS)', Environmental Innovation and Societal Transitions, 16: 73-5.

$\longrightarrow$ - — a a in Laos using the Technological Innovation Systems Approach', Technological Forecasting \& Social Change, 95(June): 218-33.

Blumer, H. (1954) 'What is Wrong with Social Theory?', American Sociological Review, 19/1: 3-10.

Borrás, S., and Edquist, C. (2013) 'The Choice of Innovation Policy Instruments', Technological Forecasting \& Social Change, 80/8: 1513-22.

Carlsson, B., Holmen, M., Jacobsson, S., Rickne, A., and Stankiewicz, R. (2002) 'The Analytical Approach and Methodology'. In: B. Carlsson (ed.) The Technological Systems in the Bioindustries. Boston, MA: Springer.

Chung, C-c. (2012) 'National, Sectoral and Technological Innovation Systems: The Case of Taiwanese Pharmaceutical Biotechnology and Agricultural Biotechnology Innovation Systems (1945-2000)', Science and Public Policy, 39: 271-81.

Cronin, M., and Weingart, L. (2007) 'Representational Gaps, Information Processing, and Conflict in Functionally Diverse Teams', Academy of Management Review, 32/3: 761-73.

Daft, R., and Lengel, R. (1986) 'Organizational Information Requirements, Media Richness and Structural Design', Management Science, 32/5: $554-71$.

Eriksson, P.-E., Patel, P., Rönnberg-Sjödin, D. et al. (2016) 'Managing Interorganizational Innovation Projects: Mitigating the Negative Effects of Equivocality through Knowledge Search Strategies', Long Range Planning, 49: 691-705.

Flanagan, K., and Uyarra, E. (2016) 'Four Dangers Innovation Policy Studies and How to Avoid Them', Industry and Innovation, 23/2: 177-88.

- — , and Laranja, M. (2011) 'Reconceptualising the "policy mix" for Innovation', Research Policy, 40/5: 702-13.

Fleming, L. (2001) 'Recombinant Uncertainty in Technological Search', Management Science, 47/1: 117-32.

Fogelberg, H., and Sandén, B. (2008) 'Understanding Reflexive Systems of Innovation: An Analysis of Swedish Nanotechnology Discourse and Organization', Technology Analysis \& Strategic Management, 20/1: 65-81.

Frishammar, J., Floren, H., and Wincent, J. (2011) 'Beyond Managing Uncertainty: Insights from Studying Equivocality in the Fuzzy Front End of Product and Process Innovation Projects', IEEE Transactions on Engineering Management, 58/3: 551-63.

Galbraith, J. (1973). Designing Complex Organizations. Boston: Addison-Wesley Longman.
Geels, F., Hekkert, M., and Jacobsson, S. (2008) 'The Dynamics of Sustainable Innovation Journeys', Technology Analysis \& Strategic Management, 20/5: 521-36.

Hellsmark, H., Mossberg, J., Söderholm, P. et al. (2016a) 'Innovation System Strengths and Weaknesses in Progressing Sustainable Technology: The Case of Swedish Biorefinery Development', Journal of Cleaner Production, 131: 702-15.

$\longrightarrow, \ldots,-$, Frishammar, J., Söderholm, P.et al. (2016b) 'The Role of Pilot and Demonstration Plants in Technology Development and Innovation Policy', Research Policy, 45: 1743-61.

Hudson, L., Winskel, M., and Allen, S. (2011) 'The Hesitant Emergence of Low Carbon Technologies in the UK: The Micro-CHP Innovation System', Technology Analysis o Strategic Management, 23/3: 297-312.

Jacobsson, S. (2008) 'The Emergence and Troubled Growth of a "biopower" Innovation System in Sweden', Energy Policy, 36/4: 1491-508.

— , and Bergek, A. (2011) 'Innovation System Analyses and Sustainability Transitions: Contributions and Suggestions for Research', Environmental Innovation and Societal Transitions, 1/1: 41-57.

Kern, F. (2015) 'Engaging with the Politics, Agency and Structures in the Technological Innovation Systems Approach', Environmental Innovation and Societal Transitions, 16: 67-9.

Kivimaa, P., and Kern, F. (2016) 'Creating Destruction or Mere Niche Support? Innovation Policy Mixes for Sustainability Transitions', Research Policy, 45: 205-17.

Klein-Woolthuis, R., Lankhuizen, M., and Gilsing, V. (2005) 'A System Failure Framework for Innovation Policy Design', Technovation, 25/6: 609-19.

Klijn, E.-H. (2005) 'Designing and Managing Networks: Possibilities and Limitations for Network Management', European Political Science, 4: 328-39.

—. Steijn, B., and Edelenbos, J. (2010) 'The Impact of Network Management', On Outcomes in Governance Networks. Public Administration, 73: 437-54.

Köhler, J., Schade, W., Leduc, G. et al. (2013) 'Leaving Fossil Fuels Behind? An Innovation System Analysis of Low Carbon Cars', Journal of Cleaner Production, 48 (June): 176-86.

Laranja, M., Uyarra, E., and Flanagan, K. (2008) 'Policies for Science, Technology and Innovation: Translating Rationales into Regional Policies in a Multi-level Setting', Research Policy, 37: 823-35.

Lehmann, P., and Söderholm, P. (2017) 'Can Technology-specific Deployment Policies be Cost-effective? The Case of Renewable Energy Support Schemes', Environmental \& Resource Economics, doi: 10.1007/s106 40-017-0169-9.

Malerba, F. (1996). Public policy and industrial dynamics: an evolutionary perspective (Innovation systems and European integration, report for EU commission).

Markard, J., Raven, R., and Truffer, B. (2012) 'Sustainability Transitions: An Emerging Field of Research and its Prospects', Research Policy, 41/6: 955-67.

Meijer, I., Hekkert, M., and Koppenjan, J. (2007) 'The Influence of Perceived Uncertainty on Entrepreneurial Action in Emerging Renewable Energy Technology; Biomass Gasification Projects in the Netherlands', Energy Policy, 35/11: 5836-54.

Metcalfe, J. S. (2005). 'Systems Failure and the Case for Innovation Policy'. In: M., Matt P., Llerena and A., Avadikyan (eds) Innovation Policy in a Knowledge Based Economy: Theories and Practice. Berlin: Springer.

Mitroff, I., and Featheringham, T. (1974) 'On Systematic Problem Solving and the Error of the third Kind', Behavioral Science, 19/6: 383-93.

Mossberg, J., Söderholm, P., Hellsmark, H., and Nordqvist, S. (2018) 'Crossing the Biorefinery Valley of Death? A Role-based Typology for Understanding Actor Networks' Ability to Overcome Barriers in Sustainability Transitions', Environmental Innovation and Societal Transitions, (forthcoming).

Musiolik, J., Markard, J., and Hekkert, M. (2012) 'Networks and Network Resources in Technological Innovation Systems: Towards a Conceptual Framework for System Building', Technological Forecasting and Social Change, 79: 1032-48. 
Negro, S., Hekkert, M., and Smits, R. (2007) 'Explaining the Failure of the Dutch Innovation System for Biomass Digestion - A Functional Aalysis', Energy Policy, 35/2: 925-38.

Nelson, R. R. (1994) 'The Co-evolution of Technology, Industrial Structure, and Supporting Institutions', Industrial and Corporate Change, 3/1: 47-63.

- , and Winter, S. (1982). An Evolutionary Theory of Economic Change. Cambridge: Cambridge University Press.

Newell, D., Sandström, A., and Söderholm, P. (2017) 'Network Management and Renewable Energy Development: An Analytical Framework with Empirical Illustrations', Energy Research and Social Science, 23: 199-210.

Nickerson, J., and Zenger, T. (2004) 'A Knowledge-based Theory of the Firm - the Problem-solving Perspective', Organization Science, 15/6: 617-32.

Palm, A. (2015) 'An Emerging Innovation System for Deployment of Building-sited Solar Photovoltaics in Sweden', Environmental Innovation and Societal Transitions, 15: 140-57.

Reichardt, K., Negro, S., Rogge, K.et al. (2016) 'Analyzing Interdependencies Between Policy Mixes and Technological Innovation Systems: The Case of Offshore Wind in Germany', Technological Forecasting \& Social Change, 106(May): 11-21.

Rogge, K. S., and Reichardt, K. (2016) 'Policy Mixes for Sustainability Transitions: An Extended Concept and Framework for Analysis', Research Policy, 45/8: 1620-35.

Schot, J., and Geels, F. (2008) 'Strategic Niche Management and Sustainable Innovation Journeys: Theory Findings, Research Agenda, and Policy', Technology Analysis \& Strategic Management, 20(x): 537-54.
Simon, H. (1969) The Sciences of the Artificial. Cambridge: MIT Press.

Stankiewicz, R., and Carlsson, B. (1991) 'On the Nature, Function and Composition of Technological Systems', Journal of Evolutionary Economics, 1/2: 93-118.

Suurs, R., and Hekkert, M. (2009) 'Cumulative Causation in the Formation of a Technological Innovation System: The Case of Biofuels in the Netherlands', Technological Forecasting \& Social Change, 76/8: 1003-20.

- - , Kieboom, S. et al. (2010) 'Understanding the Formative Stage of Technological Innovation System Development: The Case of Natural Gas as an Automotive Fuel', Energy Policy, 38/1: 419-31.

Tigabu, A., Berkhout, F., and van Beukering, P. (2015) 'Functional Evolution and Accumulation of Technological Innovation Systems: The Case of Renewable Energy in East Africa', Science and Public Policy, 42: 614-31.

Vasseur, V., Kamp, J., and Negro, S. (2013) 'A Comparative Analysis of Photovoltaic Technological Innovation Systems Including International Dimensions: The Cases of Japan and The Netherlands', Journal of Cleaner Production, 48(June): 200-10.

Weick, K. (1979). The Social Psychology of Organizing. Boston: McGraw-Hill. Wieczorek, A., and Hekkert, M. (2012) 'Systemic Instruments for Systemic Innovation Problems: A Framework for Policymakers and Innovation Scholars', Science and Public Policy, 39/1: 74-87.

Zack, M. (2001) 'If Managing Knowledge is the Solution, Then What's the Problem?'. In: Y. Malhotra (ed.) Knowledge Management and Business Model Innovation. London, UK: Idea Group Publishing. pp. 16-36. 